https://doi.org/10.46344/JBINO.2021.v10i04.03

\title{
GENETIC INVOLVEMENT IN DENTAL TREATMENT FEAR
}

\section{Donja Khodabakhshi', Cristina Pina', Ana Moura Teles', Inês Lopes Cardoso'**}

'Health Sciences Faculty, University Fernando Pessoa, Porto, Portugal

Email: mic@ufp.edu.pt

(Received on date: 17.06.2021

Date of Acceptance: 17.07.2021

Date of publication: $\mathbf{3 0 . 0 7 . 2 0 2 1 )}$

\section{ABSTRACT}

Being a global health concern, dental fear and anxiety is estimated to affect at least one in ten individuals all around the globe. Ensuing the vicious circle of dental fear comes detrimental outcomes in quality of life. Despite the wide range of knowledge concerning the environmental factors that contribute to the acquisition of dental fear and anxiety, the prevalence has not decreased, giving researchers the possibility to highlight other concomitant etiological factors. The possible hereditary or genetic component is most recently being explored, although facing tremendous dynamical elements to substantially delineate its role. The purpose of this review was to explore, reflect and call attention to the current knowledge of the genetic involvement of dental treatment fear and anxiety. Although findings mostly stress the relation between dental fear to other phenotypes giving rise to individual vulnerability, there are studies disclosing suggestive heritability rates for dental fear and anxiety.

Keywords: dental treatment fear; heritage; genetic contribution; types of fear; anxiety 


\section{Introduction}

Fear and anxiety associated with dental treatments are long known global public health concerns. These attributes have also proved to be detrimental in terms of neglective compliance to dental treatments and dental care behaviour resulting in reduced oral health and negative impact on quality of life, following "the cycle of dental anxiety" (Berggren, 1984).

Even though there is an overall concordance amongst various authors that the aetiology is multifactorial (Beaton et al., 2014), the most widely discussed theme regarding its origin is exogenous and cognitive, most easily summarized in "Rachmanns three pathways of fear", where the acquisition of the fear rises from aversive past experiences (Pavlovian conditioning), (Milosevic \& McCabe, 2015), vicarious (seeing) or informative (hearing) pathway.

Dental practitioners have over the years adapted various methods and protocols to overcome the phenomenon (Minja \& Kabahuka, 2018). Nevertheless, looking at the statistics of dental anxiety over 50 years, researchers could not find a decrease in the population (Smith \& Heaton, 2003). The efficacy of the existing management and cognitive treatment remains in controversy, thus regressing to the multifactorial aetiology, opening up the possibility of highlighting other aspects.

Researchers have suggested possible genetic variabilities in which an individual may be more or less predisposed to suffer from dental anxiety or fear. These genetic findings are often entangled with one of the following neuropsychological dynamics: fear, pain or temperamental/personality

characteristics. Considering that the heritable component of some personality disorders is remarkably high, such as General Anxiety Disorder (GAD) (McNeil et al., 2001) being dental anxiety one of its related branches, can possibly result from one of the genetic factors involved. Digging further into inheritance patterns in twins, Ray et al., (2010) showed a notable difference in heritability of dental anxiety/fear between girls and boys. This, in accordance with other findings, suggested higher numbers of dental anxiety or fear in females than in males (Randall et al., 2017; Zinke et al., 2019). Suggestively there is moderate heritability in specific phobias and candidate gene associations have been presented (Kendler et al., 1999; Gratacòs et al., 2001). Until today, studies have succeeded to outline a twice as high predictability to dental avoidance seeking behaviour, depending on the existence of a Melanocortin 1 Receptor (MCIR) gene variant (Binkley et al., 2009; Randall et al., 2016b). Remarkably, Randall et al., (2016a) demonstrated results of $30 \%$ heritability of dental fear followed by another genome-wideassociation-study where suggestive loci for dental fear associated phenotypes were presented (Randall et al., 2017).

The aim of this review was to explore and highlight the current understanding and findings of a genetic and heritability component in the aetiology of dental fear and anxiety. 


\subsection{Methods}

The relevant published literature was found and collected through the databases of MEDLINE (via Pubmed), Bon, LILACS (through BVS) and VHL via BVS. The search was made by the controlled and structural use of vocabulary terms namely MESH and DeCS (multilingual Health science descriptors). The keywords used for the search in mentioned databases were combined by boolean modifiers/operators "AND" and "OR". The timeline used was set for 1980 until 2020. Articles included were first chosen upon the abstract, followed by thorough exploration of the whole work, including meta-analyses, research articles or reviews. All those articles not aiming the purpose of this study were excluded upon reading the abstract together with those articles not written in English.

\section{Definitions and Prevalence}

The association of negative feelings toward dental settings or treatments is termed "Dental fear and anxiety", abbreviated to DFA (Campbell, 2017). The terms fear and anxiety are used interchangeably in numerous literatures, although the knowledge of how to differentiate anxiety from fear (including their different types) that might be experienced is important. It helps the dental team to build empathy with the patient and predict their behaviour patterns. However, in this context, to be able to distinguish between these two emotions is very important to try delimiting the underlying hypothetical psychogenetic components.

\subsection{Terminology}

Evolutionary viewed, both fear and anxiety promote survival (Craske, 2003). Fear is defined as the reaction towards immediate danger which involves the release of adrenaline and stimulation of the fight-or-flight response. By these means, dental fear is seen as the reaction provoked by a stimulus which has been interpreted as dangerous or threatening such as a dental drill. Anxiety is described as a more complex state of mind. It is the reaction towards a potential or hypothetical danger often associated with the sensation of incapacity to control the upcoming situation. In dental perspective this can reflect the distress felt prior upon a dental visit. (Campbell, 2017). Dental phobia, which also falls under the categorizations of specific phobia subtypes, marks an overly expressed and exaggerated, prolonged state of anxiety towards a frightful situation or object related to dentistry. Blood-injury-injection (BII) fear or phobia is a prominent fear or anxiety related to visualizing blood, an injection, an invasive medical procedure or associated to an injury (Milosevic \& McCabe, 2015). It is also worth mentioning, that there are insufficient findings concerning Bll fear and phobia that allow its separate classification from dental fear and phobia and therefore can merge into the upcoming review (LeBeau et al., 2010).

\subsection{General evidences}

There are several assessment methods for diagnosing and measuring DFA. Amongst others, there is the Corah's Dental Anxiety Scale (DAS) and the Modified Dental Anxiety Scale (MDAS) to quantify dental anxiety as low, moderate or high. 
According to these scales, severe dental anxiety implicates the possibility of phobia (Humphris et al., 1995).

Authors suggest a higher prevalence as well as a greater intensity of DFA in females than in males. Evidence repeatedly suggests that the prevalence of DFA declines with age (Ray et al., 2010; Klingberg, 1995; Randall et al., 2017), although that might not be the case in dental fear intensity which seems to remain stable. Keeping in mind that the onset of anxiety, fear or phobias can occur at any age, the estimated age of onset for Bll phobia is five to nine years old (Milosevic \& McCabe, 2015). In the case of dental fear and anxiety, Klingberg, (1995) estimated its accentuated existence between four and nine years of age, although acquisition of fear, phobias and anxieties are thought to be highly dependent on the cognitive developmental state of the child and therefore can be strongly individual (Milosevic \& McCabe, 2015).

Estimating the prevalence of and diagnosing dental anxiety and fear in the overall population comes with some interpretation obstacles due to the various assessment methods, questionnaires and geographical discrepancies involved, along with the various aspects of the human psyche (Moore, 1991). Nevertheless, the worldwide prevalence reports that at least one in ten children has some level of DFA. In northern countries the prevalence seems to be slightly lower (Cianetti et al., 2017).

\subsection{The circle of dental fear and quality of life}

On an individual level, DFA has shown detrimental outcomes and negative impact on the quality of life. In what is called "the vicious cycle of dental fear", Berggren, (1984) explained the crucial role of DFA in the avoidance seeking behaviour which would propagate a path where treatment becomes procrastinated until symptom driven. This would in turn, increase the likelihood of being subjected to more invasive, discomforting treatment and finally ascertain their negative presumptions of dentistry, regressing to the first state of avoidance behaviour again (De Jongh et al., 2011). As such, patients suffering from DFA consecutively tend to have lower overall oral health that affects their life quality. In many cases, this change in life quality is not only at the physiological and functional level but also emotional (feelings of guilt and shame) and social.

\subsection{Types of fear in dentistry}

Fear of blood-injection-injury is often present in individuals highly attentive and fearful of invasive medical procedures such as dental extractions. Dental fear and phobia have emerged into this classification due to the largely similar aspects.

Fear of pain, also known as agliophobia, may play a crucial role in the development of DFA which will be more thoroughly discussed later. Pain itself is essential for survival. It results in the retreat from a potentially harmful situation to protect oneself physically. The studies are incomplete regarding the original source of fear of pain, whether it is the painful sensation that causes the fear, the 
activities that may lead to the pain or the thought of a painful reinjury. However, the outcome of this fear is thought to be shown as excessive focus on painful stimuli, restrictive body motions or avoidance seeking behaviours from activities.

Fear of the dentist is another important factor which may lead to dental fear and anxiety. Perceiving negative judgement from the dental team, not trusting the dental professional or not establishing a fundamental

patient-operator relationship could produce anxiety in relation to dental visits. Not only is the correct, adjustable use of vocabulary advisable for correct interaction with the patient, but additionally the body language amongst other factors (Campbell, 2017).

Fear of dental instruments is one of the reported reasons why individuals refrain from visiting the dentist. This includes the shape of the instruments that could be perceived as dangerous or potentially harmful or the sound produced during the treatment (Al Atram et al., 2016).

Other fears have indeed been included in the context of DFA, such as fear of vomiting, fear of shame, fear of the dental chair amongst others. However, the restrictions in the number of pages would not allow further elaboration on all these aspects.

\subsection{Aetiology}

The aetiology of dental fear and anxiety is considered multifactorial and very complex, made up of both exogenic and endogenic aspects. The factors considered exogenous are generally summarized in "Rachman's three pathways of fear" (Milosevic \& McCabe,
2015) namely conditioning, vicarious and verbal.

The conditioning pathway suggests that a previously aversive dental experience which once stimulated an anxiety or fearful response is responsible for the association between those feelings and the trigger.

The vicarious pathway states that the fear or anxiety does not necessarily result from personal past experiences (thus is indirect). Seeing someone else experiencing that fear can be enough to trigger the feeling. For instance, a child can acquire DFA only by seeing the parent having a bad experience.

At last, in the verbal pathway, also indirect, hearing frightful stories about how others experienced the dentist may contribute to the development of DFA.

These theories, although widely accepted, are not fully substantial. Trying to predict specific phobias, by solely relying on these cognitive modelling experiences did not manage to account for the total existing variance even closely (Oosterink et al., 2009). This study raised the same question as in the work of Smith \& Heaton, (2003) that showed, over the past 50 years, no reduction of DFA in the population, despite the rising awareness and implementation of adjustments included in good dental practice. Another inevitable doubt arises from the fact that not everyone suffering from DFA remembers having a bad experience, whether directly or indirectly. Neither does everyone with a bad dental experience develop DFA (Campbell, 2017).

Nowadays, evolutionary aspects of inheriting traits, together with genetic vulnerability studies and hypothetical 
linked genes or temperamental associations are being brought into closer attention. A growing body of scientific research supports the proposition that genes and innate inherited mechanisms perhaps have more significance in the development of DFA than formerly recognized.

\section{Psychogenetics of dental fear and anxiety}

3.1. "Natural selection - on the origin of species"

From a Darwinist point of view, Gray $(1982 ; 1987)$ portrayed a theory of "inherited phobia proneness" on how mankind, via natural selection, has obtained an inherited predisposition to create phobic reactions towards specific stimuli. Correspondingly, in the "diathesis stress model of illness" Monroe and Simons, (1991) described the aetiology of specific psychological behaviours or diseases (such as irrational fears or phobias), as a result of environmental events (stressor) in addition to an already existing genetic predisposition (diathesis). Again Kendler et al., (1999) obtained results supporting these underlying approaches, emphasizing that genetic factors together with environmental ones are needed to shape clinical phobia. In the case of Bll, an outstanding observation that aims the distinction from other types, is that nearly $70 \%$ of existing cases have a family member with the same diagnosis (Beidel \& Turner, 2005). In Bll-phobia the physiological response is characterized by two phases. The first one consists of the physiological acceleration in heart rate and blood pressure, which is a common response of most phobias. The second phase (which quickly follows the first one) demonstrates a drastic decrease of the same, resulting in syncope $175 \%$ have a history of fainting) or feelings of it. This physiological response shows a heritable pattern. It is believed that a dysregulation of the autonomous nervous system makes these individuals prone to fainting upon facing the stimuli (Milosevic \& McCabe, 2015). The estimated heritability rates of Bll phobias, varies between different studies from 33 to 59\% (Milosevic \& McCabe, 2015; Van Houtem et al., 2013). Van Houtem et al., (2013) accounted for the highest rate amongst specific phobia subtypes.

Ray et al., (2010) conducted a longitudinal study encompassing 2000 Swedish twins over three years with the aim of investigating the hypothesized heritable component of dental fear and anxiety. The participants would once at the start and once at the end of the timeline, answer three questions with yes or no regarding DFA and one question about the fear intensity. The findings suggested the presence of a genetically inherited component of dental fear, higher in females than in males. The heritability of DFA seemed to decline with age for both genders, whereas the dental fear intensity remained stable in both. This is supported by other studies attempting to conceptualize heritability rates where dental fear demonstrates $30 \%$ heritability and has a higher prevalence in females than in males (Randall et al., 2016a).

\subsection{Fear of pain}

Pain itself, promotes survival and has a protective mechanism in terms of 
refraining the body from harm. The perception of pain appears to be highly individual and includes both physiological and psychological aspects that perhaps are genetically mediated, giving rise to a broad variety of pain sensitivity that can be measured (Nielsen et al., 2008; Nielsen et al., 2009; Rosier et al., 2002). The reasons for developing fear towards pain is disputable throughout the literature, encompassing speculations whether it is due to higher pain sensitivity, amongst others (Randall et al., 2017; Binkley et al., 2009). Experiencing pain and particularly higher levels of pain during dental treatment, is more likely to be reported from dental anxious subjects than those without dental anxiety (Maggirias \& Locker, 2002; Vassend, 1993). Individuals with higher anxiety sensitivity (a sensation that pain may be dangerous) tend to additionally report more fear of pain than their counterparts (Binkley et al., 2009). Arising consensus states that some temperamental traits give higher occurrence or are associated with DFA in adults, such as anxiety and neuroticism (Hakeberg et al., 2001; Vassend et al., 2011) or shyness and inhibition in children (Klingberg \& Broberg, 2007). These findings leaned towards the perception that perhaps DFA should be regarded as an additional vulnerability and to an extent heritable, in some general fears or anxiety disorders (Berggren, 1992). Amongst other fears, fear of pain is perhaps particularly closely related to DFA, given that fear of severe pain in orofacial pain patients is significantly higher than observed in controls (McNeil et al., 2001) and candidate genes have been presented, implying a higher tendency to its development (Binkley et al., 2009). The perception of pain might be influenced by variants of the gene encoding the melanocortin 1 receptor (MCIR gene) that also plays a role in the cascade of processing pain, fear and anxiety in the brain. There are five receptors of melanocortin namely: MC1R, melanocortin 2 receptor, melanocortin 3 receptor (MC3R), melanocortin 4 receptor (MC4R) and melanocortin 5 receptor (Switonski et al., 2013). The most frequent receptors found in the central nervous system are MC3R and MC4R, however, they have the same affinity for alpha-melanocyte-stimulating hormone as MC1R (Abdel-malek, 2001). The melanocortin system is found related to anxiety-like behaviour and there is a possibility that individuals carrying the MCIR gene could simultaneously express other variants of the melanocortin receptors (Chaki and Okuyama, 2005; Binkley et al., 2009). The effects of analgesia can be caused by the presence of the allelic variants more commonly expressed in the brain (Mogil, 2005).

The presence of these allele variants predisposes these individuals to the development of dental fear. Moreover, since the MCIR gene is associated with individuals with red hair, these individuals (or dark haired caucasians with a variant of this gene, which counted for almost one quarter of the dark haired included) were twice as likely to have dental avoidance seeking behaviour than those with none. Supporting this study is a crosssectional study with 817 participants genotyped for the presence of a single nucleotide polymorphism (SNP) (Randall et al., 2016b). Randall et al., (2016b) not 
only succeeded in replicating the data where the presence of MCIR alleles predicted higher DFA, but also demonstrated that the fear of pain mediated the relation between the MCIR gene and dental fear. In opposition to the consent where heightened pain sensitivity would lead to a higher fear of pain (or vice-versa) and predispose these individuals to DFA, there are studies showing close to zero correlation between DFA and pain sensitivity (Vassend et al., 2011). Instead of an increase in pain sensitivity, these authors address the possibility of correlating it with lower levels of pain tolerance (supposedly more related to behavioural states, personality traits and ongoing situations). According to Randall et al., (2016b), dental fear can possibly be maintained because of the fear of pain, regardless of whether there exists actual dental pain or not. The same authors, in another study, suggested heritability rates for dental fear and fear of pain by collecting data from a research program located in Northern Appalachia. A $34 \%$ heritability rate was suggested for fear of pain. The overall genetic impact on DFA and fear of pain, compromised in common genes, hypothetically varies between 40-72\% (Randall et al., 2016a). Heritability of dental fear was estimated to $30 \%$ which is slightly lower than the heritability for fear of pain. This moderate rate of heritability is coincident with other contemporary measures (Ray et al., 2010). Among the presented subscales, "fear of specific dental stimuli" and "fear of medical/dental pain" were the ones with highest estimates, although "fear of severe pain" also maintained its heritable significance after including the household effect in the variance (Randall et al., 2016a).

\subsection{Candidate genes and locus}

Taken into account the previous studies suggesting that fear of pain is genetically closely related to DFA but leading to different phenotypes (Randall et al., 2016a) and the fact that fear of dental pain intensity maintained stability in the studied population (Ray et al., 2010), one might question if specific genes can prime individuals to peculiar levels of fear of pain or more specifically fear of medical/dental pain.

In the first GWAS study, made to identify plausible genes with possible relations to fear of pain, three subscales were included: fear of minor pain, fear of severe pain and fear of medical/dental pain (Randall et al., 2017). The study included 990 participants from a research program in Northern Appalachia, between 12-74 years of age and tested 8.5 $\mathrm{M}$ genes for association with fear of pain. Fear of minor pain showed three associations with genetic loci on a genome-wide level. The proposed most significant locus was located on chromosome 8 (8q24.13), close to the gene encoding de transmembrane protein 65 (TMEM65 gene) (Randall et al., 2017).

Additionally, another significant locus was found on chromosome 8 , this time on the short arm (8p21.2) close to the gene encoding the neurofilament medium protein (NEFM gene) and the gene encoding the neurofilament light protein (NEFL gene). The SNP rs73547001, for this locus on chromosome 8, was found in LOC 105379330, a LOC gene, hence 
undefined and is likely to be a pseudogene (Randall et al., 2017).

The third locus (6q26), with leading SNP rs73782827, was located near the gene encoding the enzyme 1-acylglycerol-3phosphate O-acyltransferase 4 (AGPAT4 gene) and the gene encoding Parkin RBR3 ubiquitin protein ligase (PARK2 gene). Other associations of genetic loci for fear of medical/dental pain were additionally detected, however these did not reach the threshold for genome-wide significance (Randall et al., 2017).

Possibly, fear of minor pain might be the phenotype more prominent in already pain fearful individuals, in contrast to fear of severe pain or fear of dental pain which could be more normative. Furthermore, fear of minor pain could result in fear of minor dental procedures and thus, dental avoidance seeking behaviour (Randall et al., 2017).

Another noteworthy possibility is the suggested correlation of the serotonintransporter-linked polymorphic region (5$H T T L R P$ ) polymorphism and DFA (Franćeski et al., 2018). 5-HTT, a serotonin-reuptaketransporter, is codified by the SLC6A4 gene (solute carrier family 6, member 4) and localized on chromosome 17 (17q11.1-q12). Variants on its promoter region result in changes in serotonin activity. This polymorphic region has some functional allele variations such as the $S$ (for Short) insertion of 14 sequence repeats of 20-23 bp and the $L$ (Long) insertion of 16 sequence repeats of the same length. It was found that the presence of the $S$ allele results in decreased transcription of this gene, resulting in lower serotonin reuptake (Heils et al., 1995; Heils et al., 1996).
The serotonin transporter as the name suggests, is responsible for the recycling of serotonin from the synaptic cleft back to the presynaptic neuron and consequently allows the reuse of serotonin, while terminating the effects produced by it. The neurotransmitter serotonin has to a large extent been known as the hormone of happiness, albeit fitting more than 14 receptor subtypes and being able to produce opposite effects, whether pre- or postsynaptically (Hoyer et al., 2002). The amount of serotonin reuptake transporters in human brain cells is believed to be inversely proportional to serotonin effects. For the same reason, multiple pharmacotherapeutics target the serotonin transporters to inhibit or reduce their binding to serotonin (Guimarães et al., 2010). Admitting after years of research, that the precise role of serotonin is not completely understood, the 5- HTTLPR gene polymorphism is thought to play a valid role in cerebral functioning, neural evolvement, and behaviours such as negative emotions and increased anxiety (Hariri \& Holmes, 2006). In some trials, the increased binding to 5-HTT in subjects with GAD has been reported (Wee et al., 2008), whereas other authors detected decreased 5-HTT binding correlated to anxiety (Maron et al., 2004). Moreover, there is a variety of studies that found a relationship between the $S$ allele, which leads to less expression of the transporter, and anxiety related disorders or personality traits such as neuroticism (Gonda et al., 2008).

Therefore, current literature addresses the importance of the $S$ allele variant in anxiety related disorders and personality 
traits. Individuals with this type of disorders show the presence of this variant more frequently, especially in the homozygous $(S / S)$ state. Supportive studies show that the $S$ allele predicted higher neuronal activity in human brain amygdala as a result of frightful stimuli thus creating increased response towards stressful life events (Hariri et al., 2005). Franćeski et al. (2018) hypothesized that individuals carrying the $S$ allele would have higher scores in the dental anxiety and fear assessment scales, which turned out to be correct in their study. They found a positive relationship between the $S$ allele and DFA, supporting the studies where dental anxiety was partly submerged under the umbrella of broader anxiety disorders and neuroticism.

Otowa et al. (2016), to cluster common genetic effects in anxiety disorders, conducted one of the largest genetic studies to that date. The GWAS study included 18,000 unrelated individuals in 9 different samples, with all these samples showing different genome-widesignificant regions. The researchers applied two distinct methodological strategies to identify the most common genetic effects that are common to all anxiety disorders. The included "anxiety disorders" were general anxiety disorder, panic disorder, agoraphobia, social phobia and specific phobia. One of the methods used, was based on the contrast between case-control and showed the strongest relation on the noncoding locus $3 q 12.3$. This locus has not been characterised so far. The second methodological strategy, based on quantitative phenotypic factor scores, identified three SNPs within genes of genome-wide chromosome 2 (2p21). The most significant of these three genes was the one coding for calmodulin-lysine $\mathrm{N}$ methyltransferase (CAMKMT gene). The remaining mentioned genes were the gene coding for prolyl-endopeptidaselike protein (PREPL gene) which is a member of prolyl oligopeptidase family and ultimately the solute carrier family 3 member 1 (SLC3A I) gene, encoding the heavy chain of an amino acid transporter. This transporter is involved in the high-affinity, sodium-independent transport of cystine and neutral and dibasic amino acids. All these genes were reported to be expressed in the brain and there is a suggested strong possibility of these genes being related to the risk factors for anxiety disorders. More extensive analysis and individual replication of these findings are needed to understand the role of the identified loci (Otowa et al., 2016).

Gratacòs et al. (2001) presented an outstanding observation of the existence of a relationship between a duplication on chromosome 15(q24-26), referred to as DUP25, a segment of 14-17 Mb, and several anxiety disorders. The individuals included in this study were from seven large families carrying joint laxity and DUP25. This study found that almost $80 \%$ of these individuals with the mentioned duplication, also had a phobic disorder. Moreover, testing a set of phobic patients unrelated to each other, the authors found the DUP25 in 68 of 70 individuals while for the control group only 14 in 189 showed the duplication. These findings have been reported amongst the strongest associations between a psychiatric disorder and genetic polymorphism. What was not found in this 
study, despite the remarkably high association, was the presence of any linkage. The duplication could not be explained by Mendelian inheritance, due to the lack of segregation of the markers within the duplication. Since it does not segregate in this way, it was suggested that the duplication is inherited in a nonstrictly Mendelian fashion. It was additionally suggested, the existence of a large mosaic duplication resulting from a mutation occurring during cellular mitosis, that is not connected to neighbouring loci (Gratacòs et al., 2001). Nevertheless, these findings lead to a large number of questions amongst the researchers of the field who tentatively could not reproduce the same results (Tabiner et al., 2003; Zhu et al., 2004).

Moreover, chromosomes incorporate material apart from but entangled with the DNA, which successively will be transmitted with it, the epigenome (Strachan \& Read, 2011). This complement of proteins and chemical alterations will fluctuate at a specific locus and therefore affect the transgenerational descent of the epigenetic state, raising the possibility of several inherited epigenetic variants in association to the same genome. This common changeability in inherited epigenetic states to following germline is argued as a tool of phenotypic response to environmental influence and have lifted speculations about the underlying potential of its transmissions.

\section{Discussion}

The presumption that pain sensitivity is measurable (Rosier et al., 2002), considering an adequate part of the broad individual variance genetically mediated (Nielsen et al., 2008; Nielsen et al., 2009), and that patients with high levels of DFA also demonstrate higher levels of pain during treatment (Maggirias \& Locker, 2002) has been one tentative way to explore the cascade between genetic composition and DFA. This assumption that a higher pain sensitivity leads to a more painful dental treatment experience and consequently triggers the development of DFA, is perhaps the underlying assumption in Binkley's study. The resistance to the effects of local analgesics on a population carrying the MCIR gene, makes them more susceptible to experience pain during dental treatment, hence more likely to develop dental anxiety (Binkley et al., 2009). In contrast to this belief, Vassend et al. (2011) expressed the possibility of a relation between DFA and pain tolerance, which could explain why these individuals appear to have a readiness to react fearfully and withdrawn. Hypothetically, if this concept is projected on the MCIR study, it could align with their result of higher dentalcare avoidance behaviour. Regarding their other results where feasible proportions of the genetic components of DFA suggestively overlap those for neuroticism, could those variants of the MCIR gene also play a role in the aetiology of neuroticism?

Work of Binkley et al. (2009) expressed the possibility of simultaneously expressing other melanocortin receptors more frequently present in the brain, which could play a role in elevated levels of anxiety and consequently dental anxiety. However, none of the individuals in the studied population had any diagnosed 
psychological disorders (Binkley et al., 2009).

Then, there is also the question of retrospective cognitive bias, the reliability of memory estimation of pain, not directly after treatment. In the evaluation of the MCIR gene variants, Randall et al. (2016b) highlighted how it is the fear of pain, not the pain per se, which mediates the association to DFA. In fact, an association between the MCIR gene and fear of dental pain was already brought into light by Binkley et al. (2009) and both these works suggested broader studies in the field should be done. Not to forget that the questionnaires are based on selfevaluation and therefore may include levels of subjectivity. Higher levels of fear of pain seems to be consistent with orofacial pain subjects than those of control (McNeil et al., 2001) such as fear of severe pain or fear of medical/dental pain (Randall et al., 2016b). However, regarding results in the GWAS study (Randall et al., 2017), it comes off as partly diffuse since "fear of minor pain" was the only phenotype sub-category showing substantial associations to genetic loci on a genome-wide level. These two studies were both based on data collected from participants of the same research program in Northern Appalachia. Hence, the sample size and the relative demographic homogeneity of the analysed population could potentially either bypass true associations or/and bias the data of phenotypes, respectively. To their favour, although the shortage of capacity in identifying low frequency gene associations, significant associations to three genetic loci were indeed found (Randall et al., 2017).
There seems to be enough collective evidence for stating that the polygenic heritability is an important part of the fear of pain and ultimate development of dental fear. Detecting the presence of fear of pain could be an important aid for the correct detection and intervention of dental fear and phobia.

since pain is cognitively processed before being perceived, it leaves methodological difficulties in terms of distinguishing genes. In some situations, unpredicted genes have occasionally shown high associations with psychological disorders, but failed to be replicated by following studies, such as in the association of joint laxity and a DUP25, where $80 \%$ of tested patients showed a phobic disorder (Gratacòs et al., 2001; Tabiner et al., 2003; Zhu et al., 2004).

Van Houtem et al. (2013), in their metaanalysis of twin studies, estimated Bll phobia as the one with highest heritability rate amongst specific phobias, which is the one showing distinct physical signs in comparison to others. Perhaps this could serve as an indicative to the importance of genetic and biological qualifications. In the Otowa et al. (2016) study, the suggested genes reaching the threshold for genome wide significance, should be further analysed in relation to DFA in future studies.

Some authors, such as Franćeski et al. (2018), found positive relations between dental anxiety and the 5- HTLPR gene polymorphism, which may predispose these individuals to negative emotions and increased anxiety (Hariri \& Holmes, 2006). Nevertheless, the literature in the field encompassing the serotonin system, such as the neurotransmission and the 
resulting effect on the human brain or behaviour, is widely contradictory per se. This is the case of the work of van der Wee et al. (2008) that found increased binding to 5-HTT in patients with GAD, and, on the other hand, other authors detected decreased 5-HTT binding correlated to anxiety (Maron et al., 2004). This can possibly be due to the fact that serotonin is able to produce opposing effects (Hoyer et al., 2002) and should be seen more accurately as multipotential. Moreover, Smith \& Heaton (2003) did not find any decrease in dental anxiety in the population in their longitudinal study, but also did not find any increase, even though the overall general anxiety had risen.

Ray et al. (2009) marked a strong difference between inheritance of DFA in girls and boys. Results of this study supported that girls are more vulnerable to DFA than boys, raising a comprehensive question. Literature addresses affirmatively that girls show DFA more than boys while others have suggested that boys are more likely to develop phobias than girls (Campbell, 2017). If there is any gender difference, it comes together with multiple possible explanations to why it could appear in that manner. One of them being cultural gender roles, making boys more restrictive in terms of acknowledging fear, pain or associated emotions. As projected, all these findings even when highly reliable, come with individual variations and not surprisingly contradictive or supportive additional findings, giving room for tremendous pages of elaboration and future studies.
The Rubix-cube of psychogenetics and DFA

The complexity of the multifactorial aetiology of DFA (with emphasis on the multi) makes it extremely challenging to apprehend for anyone who is willing to try. With regards to the psychological means, one must face the dispute of psychological definitions in an already grey area of differential diagnostics to many times invisible - symptoms. Only to be confronted with the enormous perplexity of the latest challenges in molecular biology and genetical dynamics in addition to all the influencing environmental factors. Single chromosome rearrangements and stable Mendelian inheritance patterns for complex psychological traits are most likely overruled in the presence of polygenic inheritance, pleiotropic genes and various loci with hypothetical associations. Measuring the complexity of DFA is relied on the adhesion to various factors that many times are contradictory to one another, namely the strict scientific objectivity in methods for many times diffuse and widely individual human psyche. (Moore, 1991). No wonder that even monozygotic twins with supposedly $100 \%$ shared DNA, with the same familial and environmental factors, still have differences in behaviour, traits and personalities. Mendelian inheritance is not always sufficient for adequate explanation of the findings. As already mentioned above, the fluctuations in inherited epigenetic states to following germline, which is argued to be a phenotypic response to environmental influence, have lifted speculations about the underlying potential of its transmissions (Strachan \& Read, 2011). 
Could it, if stable, produce phenotypically fixed changes in a germline and by that also to the species, now inherited from parents to the next? Now, in the context of DFA, can the auxiliary epigenome be partly responsible for the variety of genome outcomes/expressions and the occasional associations found between some phenotypes and dental anxiety? Since inheritance of DFA seemingly is multifactorial, possibly polygenic with a sporadic penetrance only relying on Mendelian pathways would be indecisive. Nevertheless, finding a hypothetical epigenetic originator for inherited phenotype variants associated with DFA might challenge the borders of contemporary knowledge in all the involved areas of science. Still, the consistent march of development in science is not to be underestimated in what seems to be the rubix cube of dental fear and anxiety.

\section{Conclusion}

The hypothesis that a specific inherited genotype could predict the actual future existence of DFA is widely discussed and findings are still scarce to allow such a conclusion.

The sporadic associations found between inherited phenotypes and psychological means - related to, or of - DFA, are still unpolished and only give fragments of diverse possibilities. However, the consensus seems to favour heritability and genetic component involved in DFA aetiology, with a relatively stronger influential role in some individuals. A number of candidate genes, particularly those encompassing fear of pain and psychological disorders such as neuroticism, do reflect a higher tendency to be associated with dental anxiety, fear and phobia.

\section{Bibliography}

Abdel-Malek, Z. 2001. Melanocortin receptors: their functions and regulation by physiological agonists and antagonists. Cell. Mol. Life Sci. 58(3): 434441.

Al Atram, A. A., Singh, S., Bhardwaj, A., Fadalah, M. K. A. 2016. Evaluation of fear and anxiety associated with instruments and treatment among dental patients. Int. J. Contemp. Med. Res. 3(9): 26942696.

Beaton, L., Freeman, R., Humphris, G. 2014. Why are people afraid of the dentist? Observations and explanations. Med. Princ. Pract. 23(4): 295-301.

Berggren, U. 1984. Dental fear and avoidance: a study of etiology, consequences and treatment. Thesis. Goteborg, Sweden.

Berggren, U. 1992. General and specific fears in referred and self-referred adult patients with extreme dental anxiety. Behav. Res. Ther. 30: 395-401.

Beidel, D. C., Turner, S. M. 2005. Childhood anxiety disorders: A guide to research and treatment. Routledge, New York.

Binkley, C. J., Beacham, A., Neace, W., Gregg, R. G., Liem, E. B., Sessler, D. I. 2009. Genetic variations associated with red hair color and fear of dental pain, anxiety regarding dental care and avoidance of dental care. J. Am. Dent. Assoc. 140(7): 896-905.

Boffelli, D., Martin, D. 2012. Epigenetic inheritance: a contributor to species differentiation?. DNA Cell. Biol. 31(Suppl 1): S11-S16. 
Chaki, S., Okuyama, S. 2005. Involvement of melanocortin-4 receptor in anxiety and depression. Peptides 26(10): 1952-1964.

Campbell, C. 2017. Dental fear and anxiety in Pediatric patients - Practical strategies to help children cope. Springer, Glasgow. Cianetti, S., Lombardo, G., Lupatelli, E., Pagano, S., Abraha, I., Montedori, A., Caruso, S., Gatto, R., De Giorgio, S., Salvato, R. 2017. Dental fear/anxiety among children and adolescents. A systematic review. Eur. J. Pediatr. Dent. 18(2): 121-130.

Craske, M. G. 2003. Functions of fear versus anxiety. Origins of phobias and anxiety. 1st edn. Elsevier, Oxford.

De Jongh, A., Schutjes, M., Aartman, I. H. A. 2011. A test of Berggren's model of dental fear and anxiety. Eur. J. Oral Sci. 119(5): 361-364.

Franćeski, T., Karlović, D., Peitl, V., Ljubicić, R., Silić, A., Verzak, Z. 2018. Influence of the serotonergic system polymorphism on the expression of dental anxiety. Acta Clin. Croat. 57(3): 417-424.

Gratacòs, M., Nadal, M., Martín-Santos, R., Pujana, M. A., Gago, J., Peral, B., Armengol, L., Ponsa, I., Miró, R., Bulbena, A., Estivill, X. 2001. A polymorphic genomic duplication on human chromosome 15 is a susceptibility factor for panic and phobic disorders. Cell 106(3): 367-379.

Gray, J. A. 1987. The psychology of fear and stress, McGraw Hill, NewYork.

Gray, J. A. 1982. The Neuropsychology of Anxiety, Oxford University Press, New York.

Gonda, X., Fountoulakis, K. N., Juhasz, G., Rihmer, Z., Lazary, J., Laszik, A., Akiskal, H. S., Bagdy, G. (2008) Association of the $S$ allele of the 5-HTTLPR with neuroticismrelated traits and temperaments in a psychiatrically healthy population. Eur.
Arch. Psychiatry Clin. Neurosci. 259(2): 106-113.

Guimarães, F. S., Zangrossi, Jr. H., Del Bem, C. M., Graeff, F. G. 2010. Serotonin in panic and anxiety disorders. In: Muller $\mathrm{C}$, Cunningham $\mathrm{K}$ (ed) Handbook of Behavioral Neurobiology of Serotonin. $2^{\text {nd }}$ edn. Academic press, 667-685.

Hakeberg, M., Hagglin, C., Berggren, U., Carlsson, S. G. 2001. Structural relationships of dental anxiety, mood, and general anxiety. Acta Odontol. Scand. 59(2): 99-103.

Hariri, A. R., Holmes, A. 2006. Genetics of emotional regulation: the role of the serotonin transporter in neural function. Trends Cogn. Sci. 10(4): 182-191.

Hariri, A. R., Drabant, E. M., Munoz, K. E., Kolachana, B. S., Mattay, V. S., Egan, M.F., Weinberger, D. R. 2005. A susceptibility gene for affective disorders and the response of the human amygdala. Arch. Gen. Psychiatry 62(2): 146-152.

Heils, A., Teufel, A., Petri, S., Seemann, M., Bengel, D., Balling, U., Riederer, P., Lesch, K.-P. 1995. Functional promoter and polyadenylation site mapping of the human serotonin (5-HT) transporter gene. J. Neural Transm. Gen. Sect. 102(3): 247254.

Heils, A., Teufel, A., Petri, S., Stober, G., Riederer, P., Bengel, D., Lesch, K. P. 1996. Allelic variation of human serotonin transporter gene expression. J. Neurochem. 66(6): 2621-2624.

Hoyer, D., Hannon, J. P., Martin, G. R. 2002. Molecular, pharmacological and functional diversity of $5-\mathrm{HT}$ receptors. Pharmacol. Biochem. Behav. 71(4): 533554.

Humphris, G. M., Morrison, T., Lindsay, S. J. 1995. The modified dental anxiety scale: 
Validation and United Kingdom norms. Community Dent. Health 12(3): 143-150.

Hägglin, C., Hakeberg, M., Hallstrom, T., Berggren, U., Larsson, L., Waern, M., Pálsson, S., Skoog, I. 2001. Dental anxiety in relation to mental health and personality factors. A longitudinal study of middle-aged and elderly women. Eur. J. Oral Sci. 109(1): 27-33.

Kendler, K., Karkowski, L., Prescott, C. 1999. Fears and phobias: reliability and heritability. Psychol. Med. 29(3): 539-553.

Klingberg, G. 1995. Dental fear and behavior management problems in children. A study of measurement, prevalence, concomitant factors, and clinical effects. Swed. Dent. J. Suppl. 103: $1-78$.

Klingberg, G., Broberg, A. G. 2007. Dental fear/anxiety and dental behavior management problems in children and adolescents: a review of prevalence and concomitant psychological factors. Int. J. Paediatr. Dent. 17: 391-406.

LeBeau, R. T., Glenn, D., Liao, B., Wittchen, H.-U., Beesdo-Baum, K., Ollendick, T., Craske, M. G. 2010. Specific phobia: A review of DSM-IV specific phobia and preliminary recommendations for DSM-V. Depress. Anxiety 27(2): 148-167.

Maron, E., Kuikka, J. T., Ulst, K., Tiihonen, J., Vasar, V., Shlik, J. 2004. SPECT imaging of serotonin transporter binding in patients with generalized anxiety disorder. Eur. Arch. Psychiatr. Clin. Neurosci. 254: 392396.

Maggirias, J., Locker, D. 2002. Psychological factors and perceptions of pain associated with dental treatment. Community Dent. Oral Epidemiol. 30(2): 151-159.

Milosevic, I., McCabe, E. R. 2015. Family influences on the development and maintenance of Phobias. In: Milosevic I, McCabe RE (ed) The Psychology of Irrational Fear, Greenwood, California, 292-298.

Minja, I. K., Kahabuka, F. K. 2019. Dental anxiety and its consequences in oral health care delivery. In: Kocabasoglu N, Çaglayan RHB (ed) Anxiety Disorders from Childhood to Adulthood, IntechOpen, 34-36.

McNeil, D. W., Au, A. R., Zvolensky, M. J., McKee, D. R., Klineberg, I. J., Ho, C. C. 2001. Fear of pain in orofacial pain patients. Pain 89(2): 245-252.

Mogil, J. 2005. Melanocortin-1 receptor gene variants affect pain and opioid analgesia in mice and humans. J. Med. Genet. 42(7): 583-587.

Moore, R. 1991. The Phenomenon of Dental Fear - Studies in Clinical Diagnosis, Measurement and Treatment (PhD thesis). Faellestrykeriet, Aarhus University, Aarhus Denmark.

Monroe, S., Simons, A. 1991. Diathesis-stress theories in the context of life stress research: Implications for the depressive disorders. Psychol. Bull. 110(3): 406-425.

Nielsen, C. S., Stubhaug, A., Price, D. D., Vassend, O., Czajkowski, N., Harris, J. R. 2008. Individual differences in pain sensitivity: genetic and environmental contributions. Pain 136: 21-29.

Nielsen, C. S., Staud, R., Price, D. D. 2009. Individual differences in pain sensitivity: measurement, causation, and consequences. J. Pain 10: 231-237.

Oosterink, F. M. D., De Jongh, A., Aartman, I. H. 2009. Negative events and their potential risk of precipitating pathological forms of dental anxiety. J. Anxiety Dis. 23: 451-457.

Otowa, T., Hek, K., Lee, M., Byrne, E. M., Mirza, S. S., Nivard, M. G., Bigdeli, T., 
Aggen, S. H., Adkins, D., Wolen, A., Fanous, A., Keller, M. C., Castelao, E., Kutalik, Z., van der Auwera, S., Homuth, G., Nauck, M., Teumer, A., Milaneschi, Y., Hottenga, J.-J., Direk, N., Hofman, A., Uitterlinden, A., Mulder, C. L., Henders, A. K., Medland, S. E., Gordon, S., Heath, A. C., Madden, P. A. F., Pergadia, M. L., van der Most, P. J., Nolte, I. M., van Oort, F. V. A., Hartman, C. A., Oldehinkel, A. J., Preisig, M., Grabe, H. J., Middeldorp, C. M., Penninx, B. W. J. H., Boomsma, D., Martin, N. G., Montgomery, G., Maher, B. S., van den Oord, E. J., Wray, N. R., Tiemeier, H., Hettema, J. M. 2016. Metaanalysis of genome-wide association studies of anxiety disorders. Mol. Psychiatry 21(10): 1391-1399.

Randall, C. L., Shaffer, J. R., McNeil, D. W., Crout, R. J., Weyant, R. J., Marazita, M. L. 2016a. Toward a genetic understanding of dental fear: evidence of heritability. Community Dent. Oral Epidemiol. 45(1): 66-73.

Randall, C. L., McNeil, D. W., Shaffer, J. R., Crout, R. J., Weyant, R. J., Marazita, M. L. 2016b. Fear of pain mediates the association between MCIR genotype and dental fear. J. Dent. Res. 95(10): 1132-1137.

Randall, C. L., Wright, C. D., Chernus, J. M., McNeil, D. W., Feingold, E., Crout, R. J., Neiswanger, K., Weyant, R. J., Shaffer, J. R., Marazita, M. L. 2017. A preliminary genome-wide association study of painrelated fear: implications for orofacial pain. Pain Res. Management 2017: 1-12.

Ray, J., Wide Boman U, Bodin L, Berggren U, Lichtenstein P, Broberg A. G. (2010) Heritability of dental fear. J Dent Res 89(3):297-301.

Rosier, E. M., Iadarola, M. J., Coghill, R. C. 2002. Reproducibility of pain measurement and pain perception. Pain 98: 205-216.

Smith, T., Heaton, L. 2003. Fear of dental care. J. Am. Dent. Assoc. 134(8): 11011108.

Strachan, T., Read, A. 2011. Human Molecular Genetics, 4th edn CRC press, 724-726.

Switonski, M., Mankowska, M., Salamon, S. 2013. Family of melanocortin receptor (MCR) genes in mammals, mutations, polymorphisms and phenotypic effects. J. Appl. Genet. 54(4): 461-472.

Tabiner, M., Youings, S., Dennis, N., Baldwin, D., Buis, C., Mayers, A., Jacobs, P. A., Crolla, J. A. 2003. Failure to find DUP25 in patients with anxiety disorders, in control individuals, or in previously reported positive control cell lines. Am. Soc. Human Genet. 72(3): 535-538.

van Houtem, C. M. H. H., Laine, M. L., Boomsma, D. I., Lightart, L., van Wijk, A. J., De Jongh, A. 2013. A review and metaanalysis of the heritability of specific phobia subtypes and corresponding fears. J. Anxiety Dis. 27(4): 379-388.

van der Wee, N. J., van Veen, J. F., Stevens, H., van Vliet, I. M., van Rijk, P. P., Westenberg, H. G. 2008. Increased serotonin and dopamine transporter binding in psychotropic medicationnaive patients with generalized social anxiety disorder shown by 1231-beta-(4iodophenyl)-tropane SPECT. J. Nuclear Med. 49: 757-763.

Vassend, O. 1993. Anxiety, pain and discomfort associated with dental treatment. Behav. Res. Ther. 31(7): 659666.

Vassend, O., Røysamb, E., Nielsen, C. 2011. Dental anxiety in relation to neuroticism and pain sensitivity. A twin study. J. Anxiety Dis. 25(2): 302-308. 
Zinke, A., Hannig, C., Berth, H. 2019. Psychological distress and anxiety compared amongst dental patientsresults of a cross-sectional study in 1549 adults. BMC Oral Health 19(1): 27.

Zhu, G., Bartsch, O., Skrypnyk, C., Rotondo, A., Akhtar, L. A., Harris, C., Virkkunen, M., Cassano, G., Goldman, D. 2004. Failure to detect DUP25 in lymphoblastoid cells derived from patients with panic disorder and control individuals representing European and American populations. Eur. J. Human Genet. 12: 505-508. 